\title{
Evaluation of Ticarcillin/Clavulanic Acid Versus Ceftriaxone Plus Amikacin for Fever and Neutropenia in Pediatric Patients With Leukemia and Lymphoma
}

\author{
Antonio Sérgio Petrilli, Monica Cypriano, \\ Lenice Silva Dantas, Lúcia Martino Lee, \\ Maria Flávio Augusto Vercillo Luisi, \\ Katia Veronica Torres B. Silva (in memoriam) \\ and Carlos Alberto Pires Pereira
}

\author{
Pediatric Oncology Institute (GRAACC) \\ Division of Infectious Disease, Federal \\ University of São Paulo (UNIFESP), São \\ Paulo/SP, Brazil
}

\begin{abstract}
Background. The empirical use of antibiotic treatments is widely accepted as a means to treat cancer patients in chemotherapy who have fever and neutropenia. Intravenous monotherapy, with broad spectrum antibiotics, of patients with a high risk of complications is a possible alternative. Methods. We conducted a prospective open-label, randomized study of patients with lymphoma or leukemia who had fever and neutropenia during chemotherapy. Patients received either monotherapy with ticarcillin/clavulanic acid $(T)$ or ceftriaxone plus amikacin $(C+A)$. Results. Seventy patients who presented 136 episodes were evaluated, 68 in each arm of the study. The mean neutrophil counts at admission were $217 \mathrm{cells} / \mathrm{mm}^{3}(\mathrm{~T})$ and $201 \mathrm{cells} / \mathrm{mm}^{3}(\mathrm{C}+\mathrm{A})$. The mean duration of neutropenia was 8.7 days $(\mathrm{T})$ and 7.6 days $(\mathrm{C}+\mathrm{A})$. Treatment was successful without the need for modifications in $71 \%$ of the episodes in the $\mathrm{T}$ group and $81 \%$ in the $\mathrm{C}+\mathrm{A}$ group $(p=0.23)$. Treatment was considered to have failed because of death in two episodes $(3 \%)$ in the $T$ group and three episodes $(4 \%)$ in the $\mathrm{C}+\mathrm{A}$ group, and because of a change in the drug applied in one episode in the $\mathrm{T}$ group and two episodes in the $\mathrm{C}+\mathrm{A}$ group. Overall success was $96 \%(\mathrm{~T})$ and 93\% $(\mathrm{C}+\mathrm{A})$. Adverse events that occurred in group $\mathrm{T}$ were not related to the drugs used in this study. Conclusion. In pediatric and adolescent patients with leukemia or lymphoma, who presented with fever and neutropenia, during chemotherapy, ticarcillin/clavulanic acid was as successful as the combination of ceftriaxone plus amikacin. It should be considered an appropriate option for this group of patients at high risk for infections.
\end{abstract}

Key Words: Fever; neutropenia, leukemia, lymphoma, ticarcillin, ceftriaxone.

Empirical antibiotic treatment of cancer patients who develop fever and neutropenia is widely accepted [1-4].

Our experience during the last 10 years has permitted us to classify patients with fever and neutropenia into high and low-risk groups for infectious complications, according to the underlying disease. Patients with

Received on 23 May 2002; revised 17 July 2002.

Address for correspondence: Dr. Antonio Sérgio Petrilli, M.D., $\mathrm{Ph} . D$. Pediatric Oncology Institute, Universidade Federal de São Paulo - Escola Paulista de Medicina. Rua Botucatu, 743. Zip code: 04023-062 - São Paulo, SP, Brazil. Phone: +55 11 50808475. Fax:+55 11 5080-8480.E-mail: iopepm@dialdata.com.br

The Brazilian Journal of Infectious Diseases 2003;7(2):111-120 (C) 2003 by The Brazilian Journal of Infectious Diseases and Contexto Publishing. All rights reserved. leukemia and stage III and IV lymphomas were considered to be at a higher risk than patients with solid tumors and stage I and II lymphomas. For the initial empirical treatment of fever and neutropenia, we had previously established the use of ceftriaxone plus amikacin for the high-risk group and ceftriaxone (IV) or ciprofloxacin (PO), in an ambulatory setting, for the low-risk group [5-9].

Ticarcillin is a wide spectrum semi-synthetic penicillin, susceptible to inactivation by several betalactamases, while clavulanic acid is an antagonist of the beta-lactamases, avoiding enzymatic degradation of the beta-lactam antibiotics by various species of bacteria $[10,11]$.

When used simultaneously, clavulanic acid expands the antibacterial spectrum of ticarcillin, acting against 
beta-lactamases produced by Staphylococcus aureus, Gram-negative bacteria, such as Klebsiella sp., Enterobacter sp., Serratia sp., some species of Pseudomonas aeruginosa and anaerobic bacteria, such as Bacteroides fragilis [12,13].

The aim of this study was to compare the efficacy and toxicity of monotherapy with ticarcillin/clavulanic acid versus ceftriaxone plus amikacin in children and adolescents with leukemia and stage III or IV lymphoma with fever and neutropenia.

\section{Materials and Methods}

This was a prospective randomized open-label trial in pediatric and adolescent patients conducted at Pediatric Oncology Institute - GRAACC - Federal University of São Paulo - Brazil. The University Institutional Ethical Review Board approved this protocol, and written consent forms from the parents or legal guardians of all patients were obtained beforehand.

The eligible population included children and adolescents with leukemia and stage III \& IV Hodgkin and non-Hodgkin lymphomas that presented with fever and neutropenia. Fever was defined as axillary temperature higher or equal to $38^{\circ} \mathrm{C}$ or higher than $37.5^{\circ} \mathrm{C}$ on three separate occasions measured at fourhour intervals within a period of 24 hours. Neutropenia was defined as an absolute neutrophils count (ANC) $<500$ cells $/ \mathrm{mm}^{3}$ or between 500 and 1000 before the nadir of chemotherapy. Patients who developed fever during transfusion of blood products or administration of amphotericin B were not eligible.

Initial Evaluation. All patients were evaluated by medical history, complete physical exam and the following laboratory examinations: complete blood cell count, electrolytes, liver and renal function, urinalysis, urine and blood cultures, culture of suspicious lesions or secretions, chest and sinus X-rays. Cerebrospinal fluid was obtained from patients with seizures and/or an abnormal neurological exam.

Randomization. All high-risk patients who developed fever and neutropenia were randomly assigned to receive either Ticarcillin/Clavulanic acid ( T) or ceftriaxone plus amikacin $(\mathrm{C}+\mathrm{A})$. T was given intravenously at a dose of $250 \mathrm{mg} / \mathrm{kg} /$ day $\left(6 \mathrm{~g} / \mathrm{m}^{2} /\right.$ day $)$ in 4 doses. Ceftriaxone was given at $100 \mathrm{mg} / \mathrm{kg} /$ day $\left(3 \mathrm{~g} / \mathrm{m}^{2} /\right.$ day $)$ and amikacin at $15 \mathrm{mg} / \mathrm{kg} /$ day as an intravenous infusion (BID). Randomization of the treatment group was made using a random number table.

Patients were evaluated daily by physical examination, complete blood count, and weekly electrolyte, hepatic and renal function tests. Blood cultures were obtained on each day that the patient remained febrile. Chest Xrays were made when clinically indicated. At $72 \mathrm{~h}$ of hospitalization, the investigator classified the patients according to the type of infection.

Therapy was modified by including new antibiotics, antifungal or antiviral agents due to a change in the clinical status, occurrence of other clinically documented infection, persistence of fever or identification of a resistant bacterium. Amphotericin B was started when a patient persisted with fever and neutropenia for more than 7 days, or earlier when fungal infection was suspected or documented. Treatment was continued until resolution of neutropenia, defined as an ANC > 500 cells $/ \mathrm{mm}^{3}$ or until completion of an appropriate course of therapy for a defined clinical or microbiological infection.

Bacteriological isolates were identified according to standard techniques and antibiotic susceptibilities were determined by the disk diffusion method according to recommendations of the National Committee for Clinical Laboratory Standards [14].

Diagnostic Criteria and Outcome. The febrile episodes were classified into the following groups: 1 . Microbiologically documented infection including bacteremia; 2. Clinically documented infection and 3. Fever of undetermined origin (FUO) due to a possible infection (no clinical or microbiological evidence).

The clinical outcome of response of each episode was evaluated both at $72 \mathrm{~h}$ and after completion of antibiotic therapy.

Therapeutic success was defined as recovery from the episode of fever and neutropenia, with or without modification of the initial empirical antibacterial therapy 
[15]. Therapeutic failure was defined as discontinuation of the study drug and/or death resulting from a documented or presumed infection during the neutropenic episode.

Statistical Analysis. The groups were compared through an association test by the Chi-square method with the Yates correction for qualitative variables and for the quantitative variables; the Student-t test was used to compare the averages of two independent samples; the Mann-Whitney test was used instead when the suppositions of the Student-t test were not satisfied. To evaluate the suppositions of the Student-t test, the following tests were used: a) Ryan-Joiner test (to test normality)b) Bartlett's test (to evaluate the homogeneity of the variances between the different groups). A pvalue $<0.05$ was considered significant.

\section{Results}

From December 1994 to October 1996, 70 patients were registered; they presented 138 episodes of fever and neutropenia. The study was conducted with 68 episodes in the $\mathrm{T}$ group and 68 episodes in the $\mathrm{C}+\mathrm{A}$ group. Two episodes, one in each group, were excluded, one because of protocol violation and another because the ANC never fell below 500 cells $/ \mathrm{mm}^{3}$ after the initial therapy.

The age of the patients ranged from 7 months to 17.5 years, with a mean age of 6.4 years $(\mathrm{SD}=3.96)$ in the $\mathrm{C}+\mathrm{A}$ group, and from 4 to 17.4 years, with an average of 7.0 years $(S D=4.1)$ in the $T$ group. The patients characteristics, including underlying disease, disease status, age, sex, race, weight, height, concomitant medication, medical or surgical condition and neutrophil count at the time of randomization were recorded (Tables 1 and 2); the two groups were similar.

All but two patients received chemotherapy previous to entering the study. These two episodes occurred in patients with active leukemia and neutropenia at diagnosis. The underlying disease was in remission in $48(73 \%)$ and active in $20(27 \%)$ of the episodes that received $\mathrm{C}+\mathrm{A}$ and $45(66 \%)$ in remission and $23(34 \%)$ active in the T group $(\mathrm{p}=0.45)$.
In the general evaluation at the end of treatment (Table 3), 64 episodes (47.2\%) were classified as clinically documented infection (27 in the $\mathrm{C}+\mathrm{A}$ group and 37 in the $\mathrm{T}$ group) and 36 (26.4\%) microbiologically documented infection (17 in the $\mathrm{C}+\mathrm{A}$ group and 19 in the T group), comprising 100 (73.6\%) episodes of documented infections in both groups. Fever of unknown origin occurred in 36 (26.4) episodes (24 in the C+A group and 12 in the T group).

Secondary infections (those diagnosed after 72 hours of treatment) occurred in $9 \%$ of the $\mathrm{C}+\mathrm{A}$ group and in $10 \%$ of the T group. All secondary infections were microbiologically documented.

The average defervescence time was 1.9 days in the $\mathrm{C}+\mathrm{A}$ group (range 1 to 8 days) and 3.1 days in the T group (range 1 to 15 days) $(\mathrm{p}=0.125)$. The mean duration of neutropenia was 7.6 days in the $\mathrm{C}+\mathrm{A}$ group (range 1 to 30 days) and 8.7 days in the T group (range 1 to 28 days $)(\mathrm{p}=0.332)$.

Within the clinically documented infections there was a predominance of infections in the head and neck area (throat, ears, nose, eyes, and sinus in both groups); 29 (43\%) episodes in the C+A group and $30(44 \%)$ in the $\mathrm{T}$ group (Table 4). Some of the patients presented more than one focus of simultaneous infection. There was no significant association between the site of clinically documented infections and the therapy group.

Initial blood cultures were positive within $72 \mathrm{~h}$ in $8 /$ 68 cases $(11.7 \%)$ in the $\mathrm{C}+\mathrm{A}$ group and in $5 / 68$ episodes (7.3\%) in the T group (Tables 5 and 6). During this period, no fungal infection was isolated and Grampositive bacteremias were the most frequent in both groups (75 and 60\%). After $72 \mathrm{~h}$ of treatment, $11.8 \%$ (8/68 cases) positive blood cultures were recovered in the $\mathrm{C}+\mathrm{A}$ group and $10.3 \%$ (7/68 cases) in the $\mathrm{T}$ group, with a predominance of Gram-negative bacteria $(50 \%)$ in the $\mathrm{C}+\mathrm{A}$ group and fungi $(42.8 \%)$ in the $\mathrm{T}$ group (Table 5). The bloodstream was considered the primary site of infection in $18 \%$ (12/68 cases) of the $\mathrm{C}+\mathrm{A}$ group and in $12 \%$ (8/68 cases) of the T group (Tables 4 - 6). More than one agent was isolated in some cases.

Among all positive blood cultures, 13 (46.4\%) Gram-positive bacteria, $10(35.7 \%)$ Gram-negative 
Table 1. Average, standard deviation (SD), minimum and maximum values for weight, age, height and initial neutrophil counts, according to therapy groups

\begin{tabular}{lcccccccr}
\hline & \multicolumn{2}{c}{ Ceftriaxone + Amikacin } & & \multicolumn{2}{c}{ Ticarcillin/Clavulanic acid } & \\
\cline { 2 - 3 } & Average (SD) & Min-Max & & Average (SD) & Min-Max & p* \\
\hline Weight $(\mathrm{kg})$ & 22.0 & $(10.2)$ & $6.5-54.0$ & & 22.1 & $(10.3)$ & $7.2-57.4$ & 0.959 \\
Age $($ months $)$ & 77.3 & $(47.6)$ & $7-210$ & & 84.4 & $(50.0)$ & $4-209$ & 0.397 \\
Height $(\mathrm{cm})$ & $112.4(21.7)$ & $61-182$ & & 114.1 & $(23.2)$ & $70-176$ & 0.667 \\
Neutrophils $\left(/ \mathrm{mm}^{3}\right)$ & $201.2(165.0)$ & $22-481$ & & $217.0(157.0)$ & $11-440$ & 0.867 \\
\hline
\end{tabular}

*Student's T test.

Table 2. Number and percentage of patients, according to several variables and therapy type

\begin{tabular}{|c|c|c|c|c|c|c|c|c|}
\hline \multirow[b]{2}{*}{ Variable } & & \multicolumn{2}{|c|}{$\mathbf{C}+\mathbf{A}$} & \multicolumn{2}{|c|}{$\mathbf{T}$} & \multicolumn{2}{|c|}{ Total } & \multirow[b]{2}{*}{$\mathbf{p}^{*}$} \\
\hline & & $\mathbf{n}$ & $\%$ & $\mathbf{n}$ & $\%$ & $\mathbf{n}$ & $\%$ & \\
\hline \multirow[t]{6}{*}{ Diagnosis } & ALL & 40 & 58 & 37 & 6 & 77 & 57 & 0.865 \\
\hline & AML & 14 & 21 & 14 & 21 & 28 & 21 & \\
\hline & Hodgkin's III & 2 & 3 & 1 & 1 & 3 & 2 & \\
\hline & Hodgkin's IV & & & 1 & 1 & 1 & 1 & \\
\hline & Non Hodgkin's III & 9 & 13 & 10 & 13 & 19 & 13 & \\
\hline & Non Hodgkin's IV & 3 & 5 & 5 & 8 & 8 & 6 & \\
\hline \multirow[t]{2}{*}{ Disease activity } & Remission & 48 & 73 & 45 & 66 & 93 & 69 & 0.453 \\
\hline & Activity & 20 & 27 & 23 & 34 & 43 & 31 & \\
\hline \multirow{3}{*}{$\begin{array}{l}\text { Prior antimicrobial } \\
\text { treatment }\end{array}$} & & & & & & & & \\
\hline & Yes & 60 & 88 & 56 & 82 & 116 & 85 & 0.467 \\
\hline & No & 8 & 12 & 12 & 18 & 20 & 15 & \\
\hline \multirow[t]{2}{*}{ Gender } & Male & 35 & 51 & 33 & 49 & 68 & 50 & 0.864 \\
\hline & Female & 33 & 49 & 35 & 51 & 68 & 50 & \\
\hline \multirow[t]{3}{*}{ Race } & Latin & 53 & 78 & 59 & 87 & 112 & 82 & 0.300 \\
\hline & Caucasian & 1 & 1 & - & - & 1 & 1 & \\
\hline & Black & 14 & 21 & 9 & 13 & 23 & 17 & \\
\hline \multicolumn{9}{|l|}{ Concomitant } \\
\hline \multirow[t]{2}{*}{ medication } & Yes & 65 & 96 & 65 & 96 & 130 & 96 & 0.676 \\
\hline & No & 3 & 4 & 3 & 4 & 6 & 4 & \\
\hline \multirow{3}{*}{$\begin{array}{l}\text { Medical or surgical } \\
\text { condition }\end{array}$} & & & & & & & & \\
\hline & Yes & 4 & 6 & 4 & 6 & 8 & 6 & 0.716 \\
\hline & No & 64 & 94 & 64 & 94 & 128 & 94 & \\
\hline Total & & 68 & 100 & 68 & 100 & 136 & 100 & \\
\hline
\end{tabular}

* Chi-square. 
Table 3. Initial (72h) and overall evaluation by type of infection and treatment

\begin{tabular}{|c|c|c|c|c|c|}
\hline & \multicolumn{2}{|c|}{ Ceftriaxone + Amikacin } & \multicolumn{2}{|c|}{ Ticarcillin/Clavulanic acid } & \multirow[b]{2}{*}{ Total } \\
\hline & Up to $72 \mathrm{~h}$ & After 72h & Up to $72 h$ & After 72h & \\
\hline & $\mathbf{N}(\%)$ & $\mathbf{N}(\%)$ & $\mathrm{N} \quad(\%)$ & $\mathbf{N}(\%)$ & $\mathbf{N} \quad(\%)$ \\
\hline FUO & $28 \quad(41)$ & $24 \quad(35)$ & $19(28)$ & 12 (18) & $36 \quad(26.4)$ \\
\hline Clinically Documented & $29(43)$ & $27 \quad(40)$ & $37 \quad(54)$ & $37 \quad(54)$ & 64 (47.2) \\
\hline Microbiologically Documented & 11 (16) & $17 \quad(25)$ & 12 (18) & $19(28)$ & $36(26.4)$ \\
\hline Total & $68(100)$ & $68(100)$ & $68(100)$ & $68(100)$ & $136(100.0)$ \\
\hline
\end{tabular}

FUO: Fever of unknown origin.

Table 4. Primary site of infection according to therapy groups, analysed at $72 \mathrm{~h}$

\begin{tabular}{|c|c|c|c|c|c|c|}
\hline \multirow[b]{2}{*}{ Site of infection } & \multicolumn{2}{|c|}{$\mathbf{C}+\mathbf{A}$} & \multicolumn{2}{|c|}{$\mathbf{T}$} & \multicolumn{2}{|c|}{ Total } \\
\hline & & $(\%)$ & $\mathbf{N}$ & $(\%)$ & $\mathbf{N}$ & $(\%)$ \\
\hline TENES & 29 & (43) & 30 & (44) & 59 & $(43)$ \\
\hline Urinary tract & 3 & (4) & 5 & (7) & 8 & (6) \\
\hline Blood & 12 & (18) & 8 & (12) & 20 & $(15)$ \\
\hline Respiratory & 7 & (10) & 9 & (13) & 16 & (12) \\
\hline Gastrointestinal tract & 5 & $(7)$ & 3 & (4) & 8 & (6) \\
\hline Skin & 4 & (6) & 11 & (16) & 15 & (11) \\
\hline Mucositis & 15 & $(22)$ & 16 & (24) & 31 & $(23)$ \\
\hline Others & 5 & (8) & 6 & (9) & 11 & (8) \\
\hline Total episodes & 68 & (100) & & (100) & 136 & (100) \\
\hline
\end{tabular}

TENES: throat, ears, nose, eyes, sinus.

Table 5. Positive blood cultures according to therapy group and time of isolation

\begin{tabular}{|c|c|c|c|c|}
\hline \multirow[b]{3}{*}{ Isolated Agent } & \multicolumn{2}{|c|}{ Ceftriaxone + Amikacin } & \multicolumn{2}{|c|}{ Ticarcillin/Clavulanic acid } \\
\hline & Up to $72 \mathrm{hs}$ & After 72hs & Up to $72 \mathrm{hs}$ & After 72hs \\
\hline & $(\%)$ & $(\%)$ & $(\%)$ & $(\%)$ \\
\hline Gram-positive & $6 \quad(75.0)$ & $2(25.0)$ & $3(60.0)$ & 2 (28.6) \\
\hline Gram-negative & $2(25.0)$ & $4 \quad(50.0)$ & $2(40.0)$ & 2 (28.6) \\
\hline Fungi & $0 \quad(0.0)$ & $2(25.0)$ & $(0.0)$ & 3 (42.8) \\
\hline Total & $8(100.0)$ & $8(100.0)$ & $5(100.0)$ & $7(100.0)$ \\
\hline
\end{tabular}


Table 6. Isolated pathogens according to time, initial therapy and sites of isolation

\begin{tabular}{|c|c|c|c|}
\hline \multicolumn{2}{|c|}{ Ceftriaxone + Amikacin } & \multicolumn{2}{|c|}{ Ticarcillin/Clavulanic acid } \\
\hline \multicolumn{4}{|c|}{ Gram-positive Cocci: $18(41.8 \%)$} \\
\hline Within 72h & After 72h & Within 72h & After 72h \\
\hline $\begin{array}{l}\text { Streptococcus sp. (bl) (2) } \\
\text { Citrobacter freundi (bl) (1) } \\
\text { S. aureus (bl) (1) } \\
\text { S.CoN (bl) (1) } \\
\text { Enterococcus } \mathrm{sp} . \text { (bl) (1) }\end{array}$ & S.CoN (bl) (2) & $\begin{array}{l}\text { S.CoN (bl) (1) } \\
\text { S. aureus (skin) (3) } \\
\text { Streptococcus mitis (bl) (1) } \\
\text { S. aureus (bl) (1) }\end{array}$ & $\begin{array}{l}\text { S. aureus (skin) (1) } \\
\text { Enterococcus sp. (th) (1) } \\
\text { S.aureus (bl) (1) } \\
\text { S.CoN (bl) (1) }\end{array}$ \\
\hline
\end{tabular}

Total $8(42.1 \%)$

Total $10(41.7 \%)$

\begin{tabular}{|c|c|c|c|}
\hline \multicolumn{4}{|c|}{ Gram-negative Bacilli: $20(46.5 \%)$} \\
\hline Escherichia coli $(\mathrm{u})(2)$ & Salmonella sp. (bl) (1) & Escherichia coli (abs) (2) & Escherichia coli (u) (1) \\
\hline Enterobacter sp. (bl) (1) & Klebsiella sp. (bl) (2) & Klebsiella sp. (bl) (2) & Escherichia coli (bl) (1) \\
\hline \multirow{3}{*}{ Escherichia coli (bl) (1) } & Klebsiella sp. (u) (1) & Escherichia coli (u) (2) & Sthenotrophomonas \\
\hline & Escherichia coli (bl) (1) & Enterobacter sp. (abs) (1) & maltophilia (bl) (1) \\
\hline & & Proteus mirabilis $(\mathrm{u})(1)$ & \\
\hline
\end{tabular}

Total $9(47.4 \%)$

Total $11(45.80 \%)$

Fungi : $5(11.7 \%)$

Candida guilliermondii (bl) (2)

Candida albicans (bl) (1)

Rhodotorula

glutimis (bl) (1)

Candida

guilliermondii (bl) (1)

Total $2(\mathbf{1 0 . 5 \% )}$

Total $3(\mathbf{1 2 . 5 \% )}$

Total $43(100.0 \%)$

Legend: $\mathrm{bl}=$ blood $; \mathrm{u}=$ urine; abs = abscess; $\mathrm{g}=$ gastrointestinal; th $=$ throat, $\mathrm{S} . \mathrm{CoN}=$ Sthaphylococcus Coagulase Negative.

bacteria and $5(17.9 \%)$ fungi were isolated (Table 6). In $24(18 \%)$ of the 136 episodes, an indwelling central venous catheter was present ( 20 of a port-a-cath type). Of these, 12 cases were randomly assigned to the $\mathrm{C}+\mathrm{A}$ group, and 8 to the T group.

Adverse events were observed in $21(15 \%)$ episodes, 10 in the $\mathrm{C}+\mathrm{A}$ group and 11 in $\mathrm{T}(\mathrm{p}=1.000)$. The main adverse effects were gastritis, arterial hypertension, diarrhea, and vomiting. There was no correlation of the type of adverse event with the drugs used.

Some antimicrobial agents were added to the initial treatment in $33(24.2 \%)$ episodes, 13 (19\%) of the $\mathrm{C}+\mathrm{A}$ group and 20 (29\%) of the T group (Table 7). In the $\mathrm{C}+\mathrm{A}$ group, modification of therapy was indicated by clinical deterioration in 6 $(46.1 \%)$, identification of a resistant microorganism to the drugs being studied in
$3(23 \%)$ and both in $4(30.7 \%)$. In the $\mathrm{T}$ group, modification of therapy was based on clinical deterioration in $13(65 \%)$ cases, identification of a resistant microorganism in 4(15\%) and both in 3 (15\%). The changes in the antibiotics were four times more frequent in the microbiologically documented infections. There was no significant relationship between the reason that motivated the change in the therapeutic procedure and the groups being evaluated. Table 7 shows which drugs were added according to the treatment group. More than one addition was possible in each episode. The most frequently added drugs were amphotericin B (16.2\%) and vancomycin (13.2\%).

There was no significant difference between the two groups in therapeutic success $(\mathrm{p}=1.000)$, disease status $(p=0.286)$ or the presence of fever $(p=0.156)$ 
Table 7. Drug modification of initial therapy according to study group

\begin{tabular}{|c|c|c|c|c|c|c|}
\hline \multirow[b]{2}{*}{ Associated drugs } & \multicolumn{2}{|c|}{$\mathbf{C}+\mathbf{A}$} & \multicolumn{2}{|r|}{$\mathbf{T}$} & \multicolumn{2}{|c|}{ Total } \\
\hline & $\mathbf{N}$ & $(\%)$ & $\mathbf{N}$ & $(\%)$ & $\mathbf{N}$ & $(\%)$ \\
\hline Amphotericin B & 7 & $(10.2)$ & 15 & $(21.6)$ & 22 & $(16.2)$ \\
\hline Vancomycin & 7 & $(10.3)$ & 11 & (16.2) & 18 & $(13.2)$ \\
\hline Clindamycin & 2 & (2.9) & 3 & $(4.4)$ & 5 & $(3.7)$ \\
\hline Metronidazole & 5 & (7.3) & 1 & $(1.5)$ & 6 & (4.4) \\
\hline Others & 7 & $(11.8)$ & 5 & $(7.3)$ & 13 & $(9.6)$ \\
\hline Total & 28 & $(41.2)$ & 35 & $(51.5)$ & 63 & $(46.3)$ \\
\hline Episodes with addition & 13 & (19.0) & 20 & $(29.0)$ & 33 & $(24.2)$ \\
\hline Episodes without addition & 55 & $(81.0)$ & 48 & $(71.0)$ & 103 & (75.8) \\
\hline Total of episodes & & $100.0)$ & 68 & $100.0)$ & 136 & $\overline{100.0)}$ \\
\hline
\end{tabular}

Table 8. Status of the infection at the end of treatment

\begin{tabular}{lccccccc}
\hline Infection & Evolution & \multicolumn{2}{c}{$\begin{array}{c}\text { Alive without } \\
\text { change }\end{array}$} & \multicolumn{2}{c}{$\begin{array}{c}\text { Alive with } \\
\text { change }\end{array}$} & Death & \multicolumn{2}{c}{$\begin{array}{c}\text { Failure drug } \\
\text { discontinuation }\end{array}$} \\
\hline FUO & $47(34.6 \%)$ & $39(83 \%)$ & $6(12.8 \%)$ & 2 & $(4.3 \%)$ & 0 & $(0 \%)$ \\
Clin. Doc. & $66(48.5 \%)$ & $57(86.4 \%)$ & $8(12.1 \%)$ & 0 & $(0 \%)$ & 1 & $(1.5 \%)$ \\
Microb. Doc. & $23(16.9 \%)$ & $7(30.4 \%)$ & $11(47.8 \%)$ & $3(13.0 \%)$ & 2 & $(8.7 \%)$ \\
\hline Total & $\mathbf{1 3 6 ( 1 0 0 . 0 \% )}$ & $\mathbf{1 0 3}(\mathbf{7 6 \% )}$ & $\mathbf{2 5}(\mathbf{1 8 \% )}$ & $\mathbf{5}$ & $\mathbf{( 4 \% )}$ & $\mathbf{3}$ & $\mathbf{( 2 \% )}$ \\
\hline
\end{tabular}

FUO: Fever of Unknown Origin; Clin. Doc: Clinically Documented Infection; Microb. Doc.: Microbiologically Documented Infection.

Table 9. Overall response to initial therapy

\begin{tabular}{|c|c|c|}
\hline & $\begin{array}{c}\text { Ceftriaxone + Amikacin } \\
\mathbf{N}(\%)\end{array}$ & $\begin{array}{c}\text { Ticarcillin/Clavulanic acid } \\
\text { N }(\%)\end{array}$ \\
\hline Success* & $63 \quad(93.0$ & $65(96.0)$ \\
\hline Without modification & $55(81.0)$ & $48(71.0)$ \\
\hline With modification & $8(12.0)$ & $17(25.0)$ \\
\hline Failure & $2 \quad(3.0)$ & $5 \quad(7.9)$ \\
\hline Initial therapy changed & $3 \quad(4.8)$ & $1 \quad(1.0)$ \\
\hline Death & $3(4.0)$ & $2 \quad(3.0)$ \\
\hline Total & $68(100.0$ & $68(100.0)$ \\
\hline
\end{tabular}

$* \mathrm{p}=0.716$ 
in the first 72 hours, and in the overall evaluation ( $\mathrm{p}=$ 0.059).

According to the status of the infection at the end of treatment, in episodes diagnosed as FUO or Infection Clinically Documented, the patients survived and needed no change in the empirical therapy in $83 \%$ and $86 \%$ of the cases, respectively. In episodes classified as Microbiologically Documented Infections, the patients survived, but more frequently needed changes in the initial therapy (48\%); $13 \%$ of these patients died (Table 8).

Therapeutic success occurred in 93\% (63/68) of the episodes in the C+A group and $96 \%(65 / 68)$ of the $\mathrm{T}$ group $(\mathrm{p}=0.716)$. Among these, eight cases (12\%) in the C+A group and 17 (25.0\%) in the T group needed a modification in the initial empiric antibiotic regimen $(p=0.174)$. Five children died, three in the $\mathrm{C}+\mathrm{A}$ group and two in the $\mathrm{T}$ group. The cause of death was therapeutic failure in three children (two in the $\mathrm{C}+\mathrm{A}$ and one in the $\mathrm{T}$ group) and disease progression in one case in each group (Table 9).

\section{Discussion}

Onset of fever in a neutropenic patient is always an indication of a possibly serious bacterial infection. Patients with acute leukemia and stage III and IV lymphomas have a higher risk for infectious complications $[1,3]$. Underlying disease and intensive chemotherapy leads to a prolonged neutropenia, a greater frequency of bacteremia, secondary infection, and a risk of death 10 times higher than the patients classified as low-risk (solid tumors and stage I \& II lymphomas) [5,7]. These data from different studies allowed low-risk patients to be treated in an ambulatory setting, and emphasized the need of more attention for high-risk patients [6,16-19].

The use of ceftriaxone plus amikacin has been evaluated in this group of high-risk patients with satisfactory results. Because of its broad spectrum antimicrobial activity and low toxicity, Ticarcillin/ Clavulanic acid may be used as monotherapy in cancer patients $[10,12,15,17]$. In adult patients with granulocytopenia and fever there are studies describing the use of Ticarcillin/Clavulanic acid with aminoglycosides as an initial empirical therapy [10,12,20,22-24]. Ticarcillin/Clavulanic acid and tobramycin were used successfully in $72 \%$ of the Grampositive infections and $90 \%$ of the Gram-negative infections in adults in a study by Krieger et al. [21].

Schaison et al. used Ticarcillin/Clavulanic acid with netilmycin with success in $87 \%$ of the episodes in children with fever and neutropenia secondary to cancer treatment [23].

In another study of children with fever and neutropenia, Yu et al. used Ticarcillin/Clavulanic acid and gentamicin successfully in $88 \%$ of the cases, without serious toxicity or fatality. Vancomycin was added in 8 of the 17 cases in which Gram-positive bacteria were isolated [10]. In a more recent study, Gilbert et al. compared Ticarcillin/Clavulanic acid, with gentamicin as single daily dose or divided three times a day in 175 patients hospitalized with serious infections, evaluating the safety and efficacy of a dose of gentamicin according to creatinine clearance. Clinical and microbiological efficacy were similar [25]. This association is an important recommendation as initial therapy for patients with serious infections [17].

In our study, $57 \%$ of the cases occurred in patients with ALL and $21 \%$ in AML, with an average time of neutropenia of 7.6 days in the $\mathrm{C}+\mathrm{A}$ group and 8.7 days in the T group, which is comparable to our former studies [5].

In the final evaluation, $73.6 \%$ of the patients were defined as documented infections and $26.4 \%$ as FUO; these rates are lower than those observed in our former studies, and in the literature [5,7,21,23]. Of the 47 cases of FUO initially found in 72 hours, 36 remained FUO, 8 evolved to be microbiologically documented and 3 to clinically documented infection. Among the patients with clinically documented infections, the site of infection most frequently found was the head and neck (59, $43 \%)$; there were $29(43 \%)$ in the $\mathrm{C}+\mathrm{A}$ group and 30 (44\%) in the T group. The most frequently documented infections were: mucositis, sinusitis, tonsillitis and otitis, which is different from what is found in adults $[5,6,7,8]$. The addition of another antimicrobial agent was necessary in $35(51.5 \%)$ episodes in the T group and $28(41.2 \%)$ in the $\mathrm{C}+\mathrm{A}$ group. The most frequently 
used drugs were amphotericin B and vancomycin. Among the 22 (16.2\%) episodes in which amphotericin $\mathrm{B}$ was associated, fungi were isolated in 5. In 17 cases, clinical deterioration and/or clinical evidence of fungal infection was the reason for the empirical addition of this antimicrobial agent.

Vancomycin was added in $7(10.3 \%)$ episodes in the $\mathrm{C}+\mathrm{A}$ group (in 5 a Gram-positive pathogen sensitive to vancomycin was recovered and in 2 there was a clinical deterioration). In the T group, there were 11 (16.2\%) indications, 9 for Gram-positive pathogen isolation and 2 because of clinical deterioration. The addition of vancomycin in only $13.2 \%$ of the episodes confirms the non-indication for its use in initial empirical treatment.

These additions are not considered failure of the initial empiric regimen; rather they are a consequence of serious and prolonged neutropenia. The persistence of fever after the beginning of an empiric antibiotic regimen can demonstrate inadequate treatment of the infection or the development of a secondary infection. Documented infections after 72 hours of antibiotic therapy were defined as secondary infections and were diagnosed in $9(13.2 \%)$ cases of the $\mathrm{C}+\mathrm{A}$ group and $10(14.7 \%)$ of the T group (Table 6 and 7 ).

Side effects found in the $\mathrm{T}$ group were not related to the drug itself but to the underlying disease and its complications (gastritis, arterial hypertension, diarrhea and vomiting). No toxicity was observed in the $\mathrm{C}+\mathrm{A}$ group. These data agree with previous studies [5,8,9].

Five deaths occurred during this study, three in the $\mathrm{C}+\mathrm{A}$ group (two due to therapeutic failure and one due to disease progression). One patient with acute myeloid leukemia, had fever and diarrhea and a blood culture in which Salmonella sp. was isolated. She progressed to septic chock and death. The second patient, with AML in the induction phase, developed pneumonia, skin abscess, and diarrhea; coagulase negative Staphylococcus and Candida guilliermondii were isolated in his blood. $\mathrm{He}$ progressed to septic chock and death. The third patient, with ALL in second marrow relapse, died from disease progression and central nervous systembleeding.

Two deaths occurred in the $\mathrm{T}$ group, one from central nervous system bleeding in a patient with AML, the second death involved a patient with ALL in third marrow relapse, who had bleeding and fungal infection in the blood.

Overall success was documented in $96 \%$ and $97 \%$ of the $\mathrm{C}+\mathrm{A}$ and $\mathrm{T}$ groups, respectively. Success without modification was $81 \%$ in the $\mathrm{C}+\mathrm{A}$ group and $71 \%$ in the $\mathrm{T}$ group, confirming that the drugs were adequate for initial therapy.

The group of patients with microbiologicallydocumented infection required more additions to the initial empiric therapy, scoring an index of success without changes of $30.4 \%$, and $87.0 \%$ therapeutic success with modification, which is similar to what was found in other studies [10-12,20-24] (Table 8).

\section{Conclusion}

There was no toxicity associated with the drugs in this study. Therapy was well tolerated. Monotherapy with Ticarcillin/Clavulanic acid was as successful as the combination of ceftriaxone plus amikacin. In children and adolescents it should be considered an appropriate option for patients at high risk for infection.

This data is from a pediatric oncology center in a developing country, demonstrating that with effective antimicrobial therapeutic strategies and adequate clinical care it is possible to obtain results similar to those found in more privileged centers, offering an opportunity for more intense chemotherapy regimens and better survival rates for the patients.

\section{Acknowledgment}

The authors are grateful to Murali Chintagumpala MD, from Texas Children's Cancer Center, Baylor College of Medicine, for her review of this manuscript.

\section{References}

1. Pizzo P.A., Robichaud K.J., Wesley R.N., Commers J.R. Fever in the pediatric and young adult patient with cancer. A prospective study of 1001 episodes. Medicine 1982;61:153-65.

2. Bodey G.P., Buckley M., Sathe Y.S., Freireich E.J. Quantitative relationships between circulating leukocytes and infection in patients with acute leukemia. Ann Intern Med 1996;64:328-40. 
3. Robinson L.L. General principles of the epidemiology of childhood cancer. In: Pizzo PA, Poplack DG, editors. Principles and practice of pediatric oncology. $3^{\text {rd }} \mathrm{ed}$. Philadelphia: Lippincott-Raven Publishers; 1997. p 1-10.

4. Lucas K.G., Brown A.E., Armstrong D., et al. The identification of febrile neutropenic children with neoplastic disease at low risk for bacteremia and complications of sepsis. Cancer 1996;77:791-8.

5. Petrilli A.S., Melaragno R., Barros K.V.T., et al. Fever and neutropenia in children with cancer: a therapeutic approach related to the underlying disease. Pediatr Infect Dis 1993; 12:916-21.

6. Petrilli A.S., Dantas L.S., Campos M.C., et al. Oral ciprofloxacin vs. Intravenous ceftriaxone administered in an outpatient setting for fever and neutropenia in low-risk pediatric oncology patients: randomized prospective trial. Med Pediatr Oncol 2000;34:87-91.

7. Petrilli A.S., Bianchi A., Kusano E., et al. Fever and granulocytopenia in children with cancer: a study of 299 episodes with two treatment protocols in Brazil. Med Pediatr Oncol 1993;21:356-61.

8. Charnas R., Luthi A.R., Ruch W. Once daily ceftriaxone plus amikacin vs. three times daily ceftazidime plus amikacin for treatment of febrile neutropenic children with cancer. Writting Committee for the International Collaboration on Antimicrobial Treatment of Febrile Neutropenia in Children. Ped Infects Dis 1997; 16:346-53.

9. The international antimicrobial therapy cooperative group of the European organization for research and treatment of cancer. Efficacy and toxicity of single daily doses of amikacin and ceftriaxone versus multiple daily doses of amikacin and ceftazidime for infection in patients with cancer and granulocytopenia. Ann Intern Med 1993; 119:584-93.

10. Yu L.C., Shaneyfelt T., Warrier R. O. de D. The efficacy of ticarcillin clavulanate and gentamicin as empiric treatment for febrile neutropenic pediatric patients with cancer. Paediatric Hematol Oncol 1994;11:181-7.

11. Reed M.D., Yamashita T.S., Blumer J.L. Pharmacokineticbased ticarcillin/clavulanic acid dose recommendations for infants and children. Clin Pharmacol 1995;35:658-65.

12. Reed M.D. Rational prescribing of extended-spectrum penicillin beta-lactamase inhibitor combinations: focus on ticarcillin/clavulanic acid. Ann Pharmacother 1998;32:S17-21.

13. Begue P., Quiniou F., Quinet B. Efficacy and pharmacokinetics of Timentin in pediatric infections, $\mathbf{J}$ Antimicrob Chemother 1986; 17(supplC):81-91.

14. Jorgensen J.H., Ferraro M.J., Craig W.A., et al. National Committee for Clinical Laboratory Standards. Performance Standards for Antimicrobial Susceptibility Tests. $6^{\text {th }}$ ed. Approved Standard. M2-A6,17:I, NCCLS, Pennsylvania, 1997.
15. The Design, Analysis, and Reporting of Clinical Trials on the Empirical Antibiotic Management of the Neutropenic Patient - Report of a Consensus Panel from the Immunocompromised Host Society. J Inf Dis 1990; $161: 397-401$.

16. Mustafa M.M., Aquino V.M., Pappo A., et al. A pilot study of outpatient management of febrile neutropenic children with cancer at low risk of bacteremia. J Pediatr 1996; 128:847-9.

17. Kaplinsky C., Drucker M., Goshen J., et al. Ambulatory treatment with ceftriaxone in febrile neutropenic children. Isr J Med Sci 1994;30:649-51.

18. Preis S., Gobel U., Jurgens H. Outpatient treatment with ceftriaxone alone or in combination with teicoplanin in febrile neutropenic children and adolescents with cancer. J Pediatr 1997;130:500-1.

19. Rubenstein B., Rolston R., Benjamins R.S. Outpatient treatment of febrile episodes in low-risk neutropenic patients with cancer. Cancer 1993;71:3640-6.

20. Mackie M.J., Reilly J.T., Purohit S., Bartzokas C.A. A randomized trial of Timentin and tobramycin versus piperacillin and tobramycin in febrile neutropenic patients. J. Antimicrob Chemother 1986; 17(Suppl C): 219-24.

21. Krieger O., Bernhart M., Plohowich R., et al. Timentin in combination with tobramycin as empirical therapy in febrile neutropenic patients with haematological malignancies. J Antomicrob Chemother 1986; 17(Suppl C):211-7.

22. Bru J.P., Michallet M., Legrand C., et al. A prospective randomized study comparing the efficacy of Timentin alone or in combination with amikacin in the treatment of febrile neutropenic patients. J Antimicrob Chemother 1986; 17(Suppl C):203-9.

23. Schaison G., Reinert P., Leverger G., Leaute J.B. Timentin (ticarcillin and clavulanic acid) in combination with aminoglycosides in the treatment of febrile episodes in neutropenic children. J Antimicrob Chemother 1986;17(Suppl C):177-81.

24. Meunier F., Snoeck R., Lagast H., et al. Empirical antimicrobial therapy with Timentin plus amikacin in febrile granulocytopenic cancer patients. J Antimicrob Chemother 1986; 17(Suppl C): 195-201.

25. Gilbert D.N., Lee B.L., Dwarkin R.J., et al. A randomized comparison of the safety and efficacy of once-daily gentamicin or thrice-daily gentamicin in combination with ticarcillin-clavulanate Am J Med 1998; 105:3,182-91. 